\title{
Yeniden İnşa Edilen Türk Spor Sisteminde İşleyiş, Yapısal Analiz ve Çözüm Önerileri
}

Dr. Ümran BAŞAR 


\section{(C) Copyright 2020}

Bu kitabın, basım, yayın ve satış hakları Akademisyen Kitabevi A.Ş.'ne aittir. Anılan kuruluşun izni alınmadan kitabin tümü ya da bölümleri mekanik, elektronik, fotokopi, manyetik kağıt ve/veya başka yöntemlerle çoğaltılamaz, basılamaz, dağıtılamaz. Tablo, şekil ve grafikler izin alınmadan, ticari amaçh kullanılamaz. Bu kitap T.C. Kültür Bakanlı̆̆ bandrolü ile satilmaktadir.

Bu kitap Eleştirel Bir Yaklaşım ile Yeniden İnşa Edilen Türk Spor Siteminin İșleyişi, Yapısal Analizi ve Çözüm Önerileri doktora tez çalışmasından üretilmiștir.

ISBN

978-625-7275-54-5

\section{Kitap Adı}

Yeniden İnşa Edilen Türk Spor Sisteminde İşleyiş, Yapısal Analiz ve Çözüm

Önerileri

Yazar

Dr. Ümran BAŞAR

Yayın Koordinatörü

Yasin Dilmen

Sayfa ve Kapak Tasarımı

Akademisyen Dizgi Ünitesi

Yayıncı Sertifika No

47518

\section{Baskı ve Cilt}

Vadi Matbaacilık

Bisac Code

SPO000000

\section{GENEL DAĞITIM}

\section{Akademisyen Kitabevi A.Ş.}

Halk Sokak 5 / A

Yenişehir / Ankara

Tel: o312 4311633

siparis@akademisyen.com

\section{www . akade misyen.com}




\section{TEŞEKKÜR}

Çalışmamın tüm aşamalarında yardımlarını hiç bir zaman esirgemeyen, bana her daim örnek olan değerli hocam ve kıymetli danışmanım Dr. Öğr. Üyesi İbrahim Fatih YENEL'e, doktora öğrenciliğim boyunca farklı bir bakış açışı kazanmamı sağlayan Prof. Dr. A. Azmi YETİM’e, yardımlarını hiçbir zaman esirgemeyen kıymetli hocam Prof. Dr. Baki YILMAZ’a ve tüm diğer hocalarıma teşekkür ederek saygılarımı sunuyorum.

Çalışmamda yer alan analizler konusunda yardımları ve kıymetli katkıları için Eskişehir Teknik Üniversitesi Spor Bilimleri Fakültesi Spor Yöneticiliği Bölümünde görevli olan değerli arkadaşım Araş. Gör. Dr. Arif YÜCE’ye gönülden müteşekkirim.

Çalışmam için kıymetli bilgi birikimlerinden istifade ettiğim ve kapılarını bana her daim sonuna kadar açan Gençlik ve Spor Bakanlığı’nın kıymetli yöneticilerine, federasyon başkanlarına, akademi ve spor camiasının kıymetli üyelerine, basın mensuplarına değerli katkıları için minnettarım.

Akademik yaşantım ve çalışmam süresince destekleri ile beni yalnız bırakmayan eşim Evren BAŞAR’a, bu sürecin her anında benimle birlikte olan biricik oğlum Kerem Alp BAŞAR’a, dualarıyla her daim yanı başımda hissettiğim annem Hatice YAHŞİye, hayatımın her anında beni destekleyen babam Ünal YAHŞİye, hayatım boyunca duygu ve düşüncelerime önem veren, hayatımın her aşamasında örnek aldığım kıymetli ablam İrem KAZANCI’ya, beni destekleriyle yalnız bırakmayan kardeşlerim Merve YAHŞİ ve Şevval YAHŞİ'ye ve hayata dair paylaşımlarıyla tecrübelerini aktaran eniştem Muhammet Kutluhan KAZANCI'ya ve sevgili ailemin bütün üyelerine sonsuz teşekkür ederim. 
- 


\section{İÇINDEKILER}

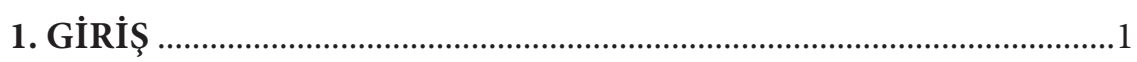

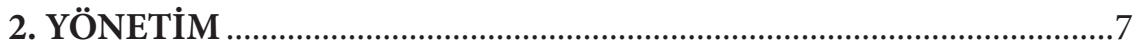

2.1. Spor Yönetimi.................................................................................

2.1.1. Türk Spor Yönetimi .....................................................................9

2.2. Türkiye’nin Spor Politikaları ……………………………………....18

2.2.1. Anayasada Spor Politikalar1 ...................................................18

2.2.2. Kalkınma Planlarında Spor ........................................................19

2.2.3. Hükümet Programlarında Spor ................................................30

3. YÖNTEM

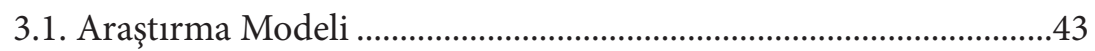

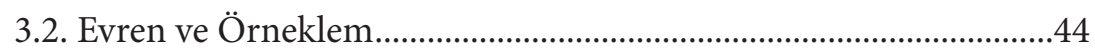

3.3. Veri Toplama Tekniği ve Aracı..............................................................44

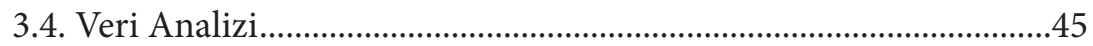

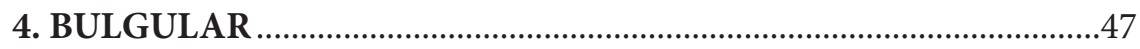

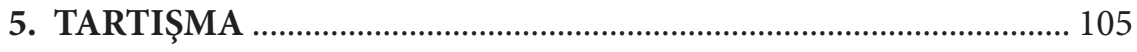

6. SONUÇ VE ÖNERILER …………………………………………...... 133

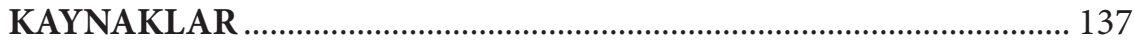


- vi - 


\section{Kisaltmalar}

BTGM: $\quad$ Beden Terbiyesi Genel Müdürlüğü

DPT: Devlet Planlama Teşkilatı

GSB: $\quad$ Gençlik ve Spor Bakanlığı

GSGM: $\quad$ Gençlik ve Spor Genel Müdürlüğü

KHK: $\quad$ Kanun Hükmünde Kararname

SGM: $\quad$ Spor Genel Müdürlüğü

TBMM: $\quad$ Türkiye Büyük Millet Meclisi

TİCI: $\quad$ Türkiye İdman Cemiyetleri İttifakı

TOHM: Türkiye Olimpiyat Hazırlık Merkezleri

TSK: $\quad$ Türk Spor Kurumu 
- 


\section{KAYNAKLAR}

1. Acar, M. (1993). Sporda hedefler ve politikalar (1923-1993). Ankara: DPT Sosyal Planlama Daire Başkanlığı, 3, 4, 24-32.

2. Akın, Y. (2004). Gürbüz ve yavuz evlatlar: Erken Cumhuriyet'te beden eğitimi ve spor. İstanbul: İletişim Yayınları, 49-171.

3. Akoğlu, H. E. Özbey, Ö. ve Polat, E. (2019). Olimpiyatlara aday olan şehirlerin adaylık süreçlerinin farklı değişkenler açısından incelenmesi (2020 olimpiyatları örneği). The Online Positioning User Service Uluslararası Toplum Araştırmaları Dergisi, 14(20), 1-1.

4. Alesina, A. and Perotti, R. (1995). Income distribution, political stability and investment. European Economic Review, 40, 1203-1220.

5. Algün-Doğu G. (2013). Yakın dönem gençlik ve spor politikalarının değerlendirilmesi. Doktora Tezi, Gazi Üniversitesi, Sağlık Bilimleri Enstitüsü, Beden Eğitimi ve Spor Anabilimdalı, Ankara: 1-88.

6. Arslan, S. (2018). Yönetim sürecinde otorite kullanımı ve ortaya çıkan sorunların değerlendirilmesi: eleştirel bir yaklaşım. Optimum Ekonomi ve Yönetim Bilimleri Dergisi, 5(1), 1-18.

7. Arslan, Ü. (2011). Siyasi istikrarsızlık ve ekonomik performans: Türkiye örneği. Ege Akademik Bakış, 11(1), 1361.

8. Atabeyoğlu, C. (1985). Tanzimat'tan Cumhuriyet'e Türkiye ansiklopedisi (6. Cilt). Tanzimat'tan Cumhuriyete Spor, İletişim Yayınları, 141-174.

9. Aydın, A. D. Demir, H. ve Yetim, A. A. (2007). Türk spor politikalarında öngörülen hedeflerin gerçekleşme düzeylerinin belirlenmesi üzerine bir araştırma (G.S.G.M. Örneği). Niğde Üniversitesi Beden Eğitimi ve Spor Bilimleri Dergisi, 1(2), 87-96.

10. Aykın, G. A., Bilir, F. P., (2013). Hükümet programları ve spor politikaları. Çukurova Üniversitesi Sosyal Bilimler Enstitüsü Dergisi, 22(2), 239-254.

11. Aytürk, G. (2005). Foucauldian panopticon in the public discourse on youth in Turkey. Master Tesis, School of Economics and Political Science University, London, 11-67.

12. Babbie, E. R. (2013). The practice of social research. Wadsworth Publishing Company, 109-126.

13. Balcı, A. ve Aydın, İ. (2003). Anadolu öğretmen liseleri için eğitim yönetimi. Ankara: Milli Eğitim Bakanlığı Yayınları, 28-76.

14. Balc1, V., Gök, Y. ve Akoğlu, H. E. (2018). Türkiye’nin ulusal gençlik ve spor politikalarının, sürdürülebilirliğin sosyal boyutuyla incelenmesi. Spor Bilimleri Araştırmaları Dergisi, 3(1), 9-22.

15. Barca, M. (2005). Stratejik yönetim düşüncesinin evrimi: Bilimsel bir disiplinin oluşum hikâyesi. Yönetim Araştırmaları Dergisi, 5(1), 7-38.

16. Basım, N. H., Argan M. (2009). Spor yönetimi. 1. Baskı, Detay Yayıncılık, Ankara, 3-26.

17. Başar, Ü. (2019). Osmanlı Olimpiyat Komitesinin Kuruluşu Hakkında Doğru Bilinen Yanlışlar. Türki İdare Dergisi. 488. 99-122.

18. Batuhan, T. (2019). 2024 Avrupa futbol şampiyonası ev sahipliği adaylıklarının değerlendirilmesi: Almanya ve Türkiye karşılaştırması. Süleyman Demirel Üniversitesi Vizyoner Dergisi, 10(25), 555-569.

19. Bilgiç, A. (2013). Stratejik yönetim düşüncesinin evrimi. Denetişim, 11, 69-75.

20. Colebatch, H.K. (2002) Concepts in social sciences: Policy (2nd Edition). Philadelphia: Open University Press, 19-147.

21. Çakır, V. O. (2017). Beylikdüzündeki sivil toplum kuruluşları ve spor kulüpleri. İstanbul: Beylik Düzü Kent Belleği, 1-27. 
22. Çevik, H. H. (2004). Türkiye de kamu yönetimi başarısızlı̆ı̆ı teorik bir yaklaşım. Ankara Üniversitesi Siyasal Bilgiler Fakültesi Dergisi, 59(03), 43-78.

23. Çolakoğlu, T. ve Erturan, E. E. (2009). Spor federasyonlarının özerkleşmeleri ve hukuksal boyutunda spor hukuku gereksinimleri. Elektronik Sosyal Bilimler Dergisi, 8(27), 323-335.

24. Çolakoğlu, T. ve Solmaz, S. (2017). Spor federasyonlarında uygulanan bağımsızlık paradoksu. Beden Eğitimi ve Spor Bilimleri Dergisi, 19(3), 24-35.

25. de Nooij, M. ve van den Berg, M. (2018). The bidding Paradox: Why politicians favor hosting mega sports events despite the bleak economic prospects. Journal of Sport and Social Issues, 42(1), 68-92.

26. Devecioğlu, S. Çoban, B. ve Karakaya, Y. E. (2011). Türkiye’de spor eğitimi sektörünün görünümü. Türk Eğitim Bilimleri Dergisi, 9(3), 627-654.

27. Devecioğlu, S. ve Çoban, B. (2005). Spor kulüplerinin sivil toplum örgütü olarak toplumsal işlevi. Siyaset ve Toplum Dergisi, 3, 181-191.

28. Devlet Planlama Teşkilatı. (1963). Birinci Beş Ylllık Kalkınma Planı 1963-1967. Ankara: DPT, 3.

29. Devlet Planlama Teşkilatı. (1968). İkinci Beş Yıllık Kalkınma Planı 1968-1972. Ankara: DPT, 1-665.

30. Devlet Planlama Teşkilatı. (1973). Üçüncü Beş Yıllık Kalkınma Planı 1973-1977. Ankara: DPT, 793.

31. Devlet Planlama Teşkilatı. (1979). Dördüncü Beş Ylllık Kalkınma Planı 1979-1983. Ankara: DPT, 155.

32. Devlet Planlama Teşkilatı. (1985). Beşinci Beş Yıllık Kalkınma Planı 1985-1989. Ankara: DPT, 150.

33. Devlet Planlama Teşkilatı. (1990). Altıncı Beş Yıllık Kalkınma Planı 1990-1994. Ankara: DPT, 296.

34. Devlet Planlama Teşkilatı. (1995). Yedinci Beş Yillık Kalkınma Planı 1996-2000. Ankara: DPT, 26- 289.

35. Devlet Planlama Teşkilatı. (2000). Sekizinci Beş Yıllık Kalkınma Planı 2001-2005. Ankara: DPT, 80-224.

36. Devlet Planlama Teşkilatı. (2006). Dokuzuncu Kalkınma Planı 2007-2013. Ankara: DPT, 1-100.

37. Devlet Planlama Teşkilatı. (2013). Onuncu Kalkınma Planı 2014-2018. Ankara: DPT, 38-49.

38. Donuk, B. (2016). Spor yönetim sanatı. İstanbul: T.C. Kültür ve Turizm Bakanlığı, 16267, 151-181.

39. Erkal, M. E., Güven, Ö. ve Ayan, D. (1998). Sosyolojik açıdan spor. İstanbul: Der Yayınları, 209-247.

40. Erturan-Ögüt, E. E. (2010). Almanya ve türkiye’deki spor klüplerinin karşılaştırılmalı analizi, türkiye'de spor kulüplerinin yapı ve işleyişine yeni bir yaklaşım. Doktora Tezi, Gazi Üniversitesi Sağlık Bilimleri Enstitüsü, Beden Eğitimi ve Spor Anabilim Dalı Ankara, 47.

41. Eşki, H. (2009). Kamu yönetiminde değişim ve yeni yönetim modelleri. Sosyal Ekonomik Araştırmalar Dergisi, 9(17), 491-500.

42. Fişek, K. (1983). Spor yönetimi. Ankara: Ankara Üniversitesi Siyasal Bilgiler Fakültesi Yayınları, 84-308.

43. Güçlü, N. (2003). Stratejik yönetim. Gazi Üniversitesi Gazi Eğitim Fakültesi Dergisi, 23(2), 61-85. 
44. Güçlü, N. ve Şehitoğlu, E. T. (2006). Örgütsel değişim yönetimi. Atatürk Üniversitesi Kazım Karabekir Eğitim Fakültesi Dergisi, (13), 240-254.

45. Gupta, R. K. and Awasthy, R. (2015). Qualitative research in management methods and experiments. New Delhi: Sage Publications, 18-278.

46. Gürsel, M. (2018). Liderlik etmenin temel ilkeleri. Konya: Eğitim Kitapevi, 28-118.

47. Howard, M. C. (1976). Management Concepts and Situations. USA: Science Research Associates, 21.

48. Işıkgöz, E. ve Taşkıran, Y. (2015). AB’ye Üyelik sürecinde türk spor yönetiminde desantralizasyon. Kastamonu Üniversitesi İktisadi ve İdari Bilimler Fakültesi Dergisi, 7(1), 6-23.

49. İmamoğlu, A. F. (1992). Fonksiyonel açıdan spor yönetiminin anlam ve önemi. Gazi University Journal of Gazi Educational Faculty, 8(1), 21-34.

50. İmamoğlu, A. F. (2002). Türkiye'de sporun yönetsel yapısı içinde spor federasyonlar. Gazi Beden Eğitimi ve Spor Bilimleri Dergisi, 16(2), 3-10.

51. İnce, M. (2016). Spor ile siyasetin ilişkisi üzerine bir analiz; Sporu siyasete alet etmek. Karabük Üniversitesi Sosyal Bilimler Enstitüsü Dergisi, 6(2), 447-455.

52. İnternet: 57. Hükümet Programi, (1999). Web: http://www.tbmm.gov.tr/hukumetler/ HP57.htm, Son Erişim Tarihi: 21.01.2018.

53. İnternet: 58. Hükümet Acil Eylem Planı, (2003). Web: http://www.kalkinma.gov.tr/ Lists/EylemVeDigerPlanlar/Attachments/13/58.HükümetAcilEylemPlanı.pdf, Son Erişim Tarihi:19.01.2018.

54. İnternet: 58. Hükümet Programı (2002). Web: http://www.tbmm.gov.tr/hukumetler/ HP58.htm, Son Erişim Tarihi: 21.01.2018.

55. İnternet: 59. Hükümet Programı, (2003). s.6,27. Web: https://www.akparti.org.tr/upload/documents/59uncu-hukumet-programi.pdf, Son Erişim Tarihi:19.01.2018.

56. İnternet: 60. Hükümet Programı Eylem Planı, (2008). Web: http://www.kalkinma.gov. tr/Lists/EylemVeDigerPlanlar/Attachments/4/60.HükümetProgramıEylemPlanı.pdf, Son Erişim Tarihi: 19.01.2018.

57. İnternet: 60. Hükümet Üç Aylık Eylem Planı, (2007). Web: http://www.kalkinma.gov.tr/ Lists/EylemVeDigerPlanlar/Attachments/5/60.Hükümet2007YılıÜçAylıkEylemPlanı. pdf, Son Erişim Tarihi:19.01.2018.

58. İnternet: 61. Hükümet Programı, (2011). Web: http://www.resmigazete.gov.tr/eskiler/2011/07/20110717-1.htm, Son Erișim Tarihi: 19.01.2018.

59. İnternet: 62. Hükümet Programi, (2014). Web: http://www.basbakanlik.gov.tr/Forms/_ Global/_Government/pg_GovernmentProgram.asp, Son Erişim Tarihi: 19.01.2018.

60. İnternet: 638 Sayılı KHK, (2011). Gençlik ve Spor Bakanlığının Teşkilat ve Görevleri Hakkında Kanun Hükmünde Kararname Web: http://www.resmigazete.gov.tr/eskiler/2011/06/20110608m1-6.pdf, Son Erişim Tarihi: 05.01.2018.

61. İnternet: 64. Hükümet Programı (2015). Web: https://www.aa.com.tr/uploads/ TempUserFiles/64.hukumet_programi.pdf, Son Erişim Tarihi: 19.01.2018.

62. İnternet: 65. Hükümet Programı (2016). Web: https://webdosya.csb.gov.tr/db/strateji/ icerikler/65-hukumet-programi 20180125142728.pdf, Son Erişim Tarihi: 19.01.2018.

63. İnternet: Antrenör Eğitimi Yönetmeliği (2019, 14 Aralık). Resmi Gazete (Sayı: 30978). Web: http://www.tdsf.gov.tr/assets/files/4c8034c03aca82dc3d59d794bcf06ab4.htm, Son Erişim Tarihi: 14.12.2019.

64. İnternet: Büyüköztürk, Ş (2012). Örnekleme Yöntemleri. Ders Notu. Web: http://w3. balikesir.edu.tr/ msackes/wp/wp-content/uploads/2012/03/BAY-Final-Konulari.pdf, Son Erişim Tarihi: 15.08.2019. 
65. İnternet: Gençlik ve Spor Bakanlığı. (2019). Teşkilat şeması. Web: http://gsb.gov.tr/ Sayfalar/35/10/TeskilatveGorevleri, Son Erişim Tarihi: 10.10.2019.

66. İnternet: GSB (2018). Gençlik ve Spor Bakanllğı 2018 Faaliyet Raporu Web: http:// www.gsb.gov.tr/public/edit/files/strateji/faaliyet-raporu-2018-090819.pdf, Son Erişim Tarihi: 10.12 .2019 .

67. İnternet: GSB (2019a). Mahalle Tipi Spor Sahalarınin Sayısı Hizla Artıyor, Web: https:// www.gsb.gov.tr/haberdetaylari/1/163399/mahalle-tipi-spor-sahalarinin-sayisi-hizla-artiyor.aspx, Son Erişim Tarihi:12.12.2019.

68. İnternet: GSB (2019b). Bakan Kasapoğlu: "Bürokratik Karmaşaların Önüne Geçtik" Web: https://www.gsb.gov.tr/haberdetaylari/3/181996/bakan-kasapoglu-burokratik-karmasalarin-onune-gectik.aspx, Son Erişim Tarihi: 25.12.2019.

69. İnternet: GSB (2019c). "Spor Kulüpleri ve Federasyonları Çalıştayı Sona Erdi” Web: https://www.gsb.gov.tr/HaberDetaylari/3/181985/spor-kulupleri-ve-federasyonlari-calistayi-sona-erdi.aspx, Son Erişim Tarihi:30.01.2020.

70. İnternet: GSB (2019d). "Üniversiteler Toplumların Gelişimi İçin Lokomotif Görevi Görür" Web: https://gsb.gov.tr/HaberDetaylari/3/158802/aaaaaa, Son Erişim Tarihi:30.12.2019

71. İnternet: GSB (2019e). Milli Sporculara "Tam Burslu Eğitim” Müjdesi Web: https://www. gsb.gov.tr/HaberDetaylari/3/1/177802/milli-sporculara-tam-burslu-egitim-mujdesi. aspx, Son Erişim Tarihi:15.01.2020.

72. İnternet: GSB (2019f). Antrenör Eğitimi Müfredat Programı Güncelleniyor Web: https:// www.gsb.gov.tr/HaberDetaylari/3/181594/antrenor-egitimi-mufredat-programi-guncelleniyor.aspx, Son Erişim Tarihi:.01.25.2020.

73. İnternet: GSB (2011). Web: http://bilgiedinme.gsb.gov.tr/Dokuman/4.5.638.pdf, Son Erişim Tarihi: 01.25.2020.

74. İnternet: Gözler, K. (2017). Cumhurbaşkanliğı sistemi mi, başkanlık sistemi mi, yoksa neverland sistemi mi? 16 nisan'da neyi oylayacağız? Web: http://www.anayasa.gen.tr/ neverland.pdf, Son Erişim Tarihi: 02.24.2017.

75. İnternet: Neziroğlu, I., Yılmaz, T., (2013). Hükümetler, Programları ve Genel Kurul Görüşmeleri, Cilt 10 (11 Ocak 1999) Türkiye Büyük Millet Meclisi Başkanlığı Yayınları Web: https://www.tbmm.gov.tr/yayinlar/hukumetler/hukumetler_cilt_10.pdf, Son Erişim Tarihi: 12.10.2019.

76. İnternet: SBB (2018). 2019 Yılı Cumhurbaşkanlığı Yıllık Programı Web: https:// www.sbb.gov.tr/wpcontent/uploads/2018/11/2019_Yili_Cumhurbaskanligi_Yillik_ Programi.pdf, Son Erişim Tarihi:10.08.2019.

77. İnternet: Sporcu Lisans, Vize ve Transfer Yönetmeliği. (2019, 14 Aralık). Resmi Gazete (Say1: 30978). Web: http://www.tdsf.gov.tr/assets/files/e6dfb68fbda3395ea591f09d2daf39f1.htm, Son Erişim Tarihi: 14.12.2019.

78. İnternet: Sunay, H. (2019a). Spor yönetimi ders notlar, Türkiye'de spor yönetimi (2). Açık Ders Malzemeleri. Web: https://acikders.ankara.edu.tr/pluginfile.php/10775/ mod_resource/content/0/\%282\%29\%20T\%C3\%9CRK\%C4\%B0YEDE\%20SPOR\%20 Y\%C3\%96NET\%C4\%B0M\%C4\%B0.pdf

79. İnternet: Sunay, H. (2019b). Spor yönetimi ders notlarl, Türk Spor Sisteminin YapılandırılmasıveBazıÜlkelerleKarşılaştırılması(3).Web:https://acikders.ankara.edu. tr/pluginfile.php/61110/mod_resource/content/0/\%283\%29\%20T\%C3\%9CRK\%20 SPOR\%20S\%C4\%B0STEM\%C4\%B0N\%C4\%B0N\%20YAPILANDIRILMASI\%20 VE\%20BAZI\%20\%C3\%9CLKELERLE\%20KAR\%C5\%9EILA\%C5\%9ETIRILMASI. pdf 
80. İnternet: T.C. Cumhurbaşkanlı̆̆ı Strateji ve Bütçe Başkanlı̆̆ (2019). On Birinci Kalkınma Planı 2019-2023 Web: http://onbirinciplan.gov.tr/, Son Erișim Tarihi: 20.10.2019.

81. İnternet: T.C. Cumhurbaşkanlı̆̆ı Strateji ve Bütçe Başkanlı̆̆l, 2020 Yll Merkezi Yönetim Bütçe Kanunu Teklifi ve Bağll Cetveller. Web: http://www.sbb.gov.tr/wp-content/ uploads/2019/10/2020_Yili_Merkezi_Yonetim_Butce_Kanunu_Teklifi_ve_Bagli_ Cetveller-1.pdf, Son Erişim Tarihi: 20.10.2019.

82. Kahraman, A. (1995). Osmanl devletinde spor (Birinci Baskı). Ankara: T.C. Kültür Bakanlığ $1,698-710$.

83. Karaca, S. (2012). Türkiye’deki büyük ölçekli spor organizasyonlarının kentin kültürel gelişimine etkileri: Trabzon ve Erzurum örnekleri. TMMOB Şehir Plancıları Odası Yayını, 4, 42-47.

84. Karakaya, Y. E. ve Karataş, B. (2017). The current state and needs of postgraduate education in sport sciences. Kastamonu Education Journal, 25(4), 1469-1482.

85. Karataş, Ö. (2014). Türkiye’de futbol ve siyaset ilişkisi. İnönü Üniversitesi Beden Eğitimi ve Spor Bilimleri Dergisi, 1(2), 39-47.

86. Kocamaz, S., Çolakoğlu, T. ve Erturan-Öğüt, E. E. (2013). Türk Spor Federasyonlarının Özerklik Sonrası Değişimi. Gazi Beden Eğitimi ve Spor Bilimleri Dergisi, 18(1-4), 7-26.

87. Koçel, T. (2018). İşletme yöneticiliği (On Yedinci Basım). İstanbul: Beta Yayınları, 397-400.

88. Kwasniewska, J. and Necka, E. (2004). Perception of the climate for creativity in the workplace: The role of the level in the organization and gender. Creativity and Innovation Management, 13(3), 187-196.

89. Miles, M. B. and Huberman, A. M. (1994). Qualitative data analysis: An expanded sourcebook (2nd ed). Thousand Oaks, CA: Sage, 1-354.

90. Ögüt, E. E. (2014). Türkiye’de spor yönetiminin neoliberal dönüşümü. Amme İdaresi Dergisi, 47(4), 31-58.

91. Öncel, A. (2018). Uluslararası spor organizasyonlarının sosyoekonomik etkileri: 2012 Londra olimpiyatları örneği ve Türkiye için bir değerlendirme. Gümüşhane Üniversitesi Sosyal Bilimler Enstitüsü Elektronik Dergisi, 8(22), 357-375.

92. Özdemir, S., Başel, H., ve Şenocak, H. (2009). Sivil toplum kuruluşları (STK)'nın artan önemi ve üsküdar'da faaliyet gösteren bazı STK'lar üzerine bir araştırma. Sosyal Siyaset Konferansları Dergisi, 56, 151-234.

93. Özen, G., Koçak, F., Boran, F., Sunay, H., ve Gedikli, N., (2012). Türk spor yönetimindeki mevcut sorunlara ilişkin akademisyenlerin görüşlerinin değerlendirilmesi. Spormetre Beden Eğitimi ve Spor Bilimleri Dergisi, X(4), 107-116.

94. Özer, U. ve Çolakoğlu, T. (2017). Çağdaş spor bilincinin oluşmasına ilişkin spor yöneticilerinin görüşleri. Ulusal Spor Bilimleri Dergisi, 1(2), 1-11.

95. Öztürk F. (1998). Toplumsal boyutlarıyla spor. Ankara: Bağırgan Yayınevi, 62-71.

96. Palazoğlu A., (1999). Atatürk 'ün eğitim ile ilgili düsünceleri, Türkiye Cumhuriyeti nin 75. yıl dönümüne armağan. Ankara: T.C. Milli Eğitim Bakanlığı Eğitim Araçları ve Donatım Dairesi Başkanlığı, 306.

97. Park, S. U. Yoon, S., Chung, S., ve Park, J. H. (2019). Is hosting a sporting mega-event ever worth it to the host city? Impact of hosting sporting mega-events on residents' sense of community. South African Journal for Research in Sport, Physical Education and Recreation, 41(3), 63-73.

98. Parrish, R., (2003), Sports law and policy in the european union. Manchester: Manchester University Press, 61-227. 


\section{Kaynaklar}

99. Patching, K. (1999). Management and organisation development beyond arrows. Basingtoke, Macmillan: Boxes and Circles, 226.

100. Poynter, G. and Viehoff, V. (2016). Introduction: Cities and sports mega-events. Megaevent cities: Urban legacies of global sports events. London: Routledge. 21-28.

101. Resmi Gazete, (2017). 6771 sayılı Türkiye Cumhuriyeti Anayasasında değisşiklik yapılmasına dair kanun. 11 Şubat 2017, 29976.

102. Resmi Gazete, (2018a). 703 nolu Anayasada yapılan değişikliklere uyum sağlanması amacıyla bazı kanun ve kanun hükmünde kararnamelerde değişiklik yapılması hakkında kanun hükmünde kararname. 9 Temmuz 2018, 30473 (3. Mükerrer).

103. Resmi Gazete, (2018b). 1 nolu cumhurbaşkanlığ teşkilatı hakkında cumhurbaşkanlığı kararnamesi. 10 Temmuz 2018, 30474.

104. Resmi Gazete, (2018c). 4 nolu bakanliklara bağh, ilgili, ilişkili kurum ve kuruluşlar ile diğer kurum ve kuruluşların teşkilatı hakkında cumhurbaşkanlı̆̆ı kararnamesi. 15 Temmuz 2018, 30479.

105. Resmi Gazete, (2019). 27 nolu bazı cumhurbaşkanlı̆̆ı kararnamelerinde değişiklik yapılması hakkında cumhurbaşkanlı̆̆ kararnamesi. 10 Ocak 2019, 30651.

106. Saban, A. ve Ersoy, A. (2019). Eğitimde nitel araştırma desenleri. Ankara: Anı Yayıncılık, 3. Bask1, 327-357.

107. Sivrikaya, K. ve Demir, A. (2019). Türkiye'de 2001 yılı ve sonrasında uygulanan spor ekonomisi politikalarına yönelik bir değerlendirme. Süleyman Demirel Üniversitesi Vizyoner Dergisi, 10(23), 126-136.

108. Solberg, H. A. and Ulvnes, A. M. (2017). Major sports events: The reasons for hosting them. European Journal of Sport Studies, 4, 1-2.

109. Solmaz, S. ve Yetim, A. A. (2018). Yeni Kamu Yönetimi Anlayışı Bağlamında Türk Spor Yapılanmasındaki Değişimin Değerlendirilmesi. Spormetre, 16(3), 7-19.

110. Sönmez, H. G. (2014). Özerklik sonrası 3289 sayılı kanunda yapılan değişikliklerin spor federasyonlarının yapılanmasına etkisi. Yüksek Lisans Tezi, Aksaray Üniversitesi Sosyal Bilimler Enstitüsü, Aksaray, 19-64.

111. Stewart, C. J. and Cash, W. B. (2008). Interviewing: Principles and practices. Boston, MA: McGraw-Hill, 47-95.

112. Sunay, H. (2002). Türkiye’de sporun yaygınlaştırılması kapsamında çağdaş spor yöneticilerinin rolü ve önemi. 7. Uluslararası Spor Bilimleri Kongresi, Bildiri kitapçığı, Antalya, 263-272.

113. Sunay, H. (2009). Spor yönetimi, Ankara: Gazi Kitabevi, 317-321.

114. Sunay, H. (2017). Spor yönetimi (3. Baskı). Ankara: Gazi Kitabevi, 287-290.

115. Sunay, H. (2019). Spor yönetimi ders notları, Açık Ders Malzemeleri.

116. Sunay, H., Boz, M. M., ve Gürbüz, P. (2002). Türkiye’de spor yöneticisi yetiştiren üniversitelerin lisans programlarının karşılaştırmalı olarak incelenmesi. Gazi Beden Eğitimi ve Spor Bilimleri Dergisi, 7(1), 56-66.

117. Şahin, M. Y. ve İmamoğlu, A. F. (2011). Akademisyenlerin ve milletvekillerinin spor siyaset etkileşimine yönelik görüşleri. Gazi Beden Eğitimi ve Spor Bilimleri Dergisi, 16(2), 25-44.

118. Tarakçıŏglu, S. ve Elmas, S. (2019). Türkiye’nin Olimpiyat Adaylıkları Üzerine Nitel Bir Araştırma. Gaziantep Üniversitesi Spor Bilimleri Dergisi, 4(3), 304-318.

119. Tayga, Y. (1990). Türk spor tarihine genel bakış. Ankara: T.C. Başbakanlık Gençlik ve Spor Genel Müdürlüğü, Yayın No:87, 124-128.

120. Tinaz, C., Leopkey, B., ve Salisbury, P. (2018). Kaybederken kazanabildik mi? İstanbul'un başarısızlıkla sonuçlanan olimpiyat adaylıklarının çıktılarının incelenmesi. SPORMETRE Beden Eğitimi ve Spor Bilimleri Dergisi, 16(4), 205-224. 
121. Tosun, K. (1974). İşletme yönetimi, genel esaslar (Cilt 1). İstanbul: İstanbul Üniversitesi, İşletme İktisadi Enstitüsü Yayını, 5.

122. Tunçer, P. (2013). Değişim Yönetimi Sürecinde Değişime Direnme. Ondokuz Mayıs Üniversitesi Eğitim Fakültesi Dergisi, 32(1), 373-406.

123. Turan, M., A. (2018). Türkiye’nin yeni yönetim düzeni: Cumhurbaşkanlığ hükümet sistemi. Social Sciences Research Journal, 7(3), 42-91.

124. Tutum, C. (1994). Kamu yönetiminde yeniden yapılanma. Ankara: TESAV Yayınları, Yayın No: 3, 5-21.

125. Ulusal Gençlik ve Spor Politikası Belgesi. (2013). Resmi Gazete, Ankara: Gençlik ve Spor Bakanlığı Yayını, No:57, 1-73.

126. Yağmurlu, A. (2019). Kamu diplomasisi bakışından spor diplomasisi. Gaziantep University Journal of Social Sciences, 18(4), 1367-1380.

127. Yahşi, Ü. (2010). Beden Eğitimi ve spor yüksekokulu öğrencilerinin değer yönelimleri. Yayımlanmamış Lisans Tezi, Ankara Üniversitesi, Beden Eğitimi ve Spor Yüksekokulu, Spor Yöneticiliği Bölümü, Ankara, 1-4.

128. Yahşi, Ü. (2014). Gençlik ve spor bakanlığı personelinin örgüt iklimi algıları ile örgütsel yaratıcılık düzeyi. Yüksek Lisans Tezi, Ankara Üniversitesi, Sağlık Bilimleri Enstitüsü, Ankara, 1-10.

129. Yenel, İ. F., İmamoğlu, F. (1998). Gençlik ve spor genel müdürlüğünün bazı çalışma alanlarında yetkili olması gereken yönetsel birimlerin yönetim kademelerince belirlenmesi. Gazi Beden Eğitimi ve Spor Bilimleri Dergisi, 3(4), 65-80.

130. Yenel, İ. F., \& Parasız, Ö. (2019). Türk spor yönetimi. A. Azmi Yetim (Ed.). Yönetim ve spor. Ankara: Gazi Kitapevi, 307-372.

131. Yetim A. A. ve Şenel, Ö. (2001). Türkiye’de spor yöneticisi yetiştirme faaliyetlerinin görünümü. Milli Eğitim Dergisi, 150, 39-45.

132. Yetim, A. A. (2014). Sosyoloji ve spor. Ankara: Berikan Yayınevi, 54-56.

133. Yetim, A. A. (2019). Türkiye’nin spor politikaları. A. Azmi Yetim (Ed.). Yönetim ve spor. Ankara: Gazi Kitapevi, 373-430.

134. Yıldırım, A., ve Şimşek, H. (2013). Sosyal bilimlerde nitel araştırma yöntemleri. Ankara: Seçkin Yayıncilık, 45-252.

135. Yıldız, G. (2016). Türk kamu yönetiminde liyakat ilkesi. Gazi Üniversitesi Sosyal Bilimler Dergisi, 3(8), 140-180.

136. Yüce, A., Balc1, V. and Katırc1, H. (2019). Evaluation of sports education at higher education level in the scope of total quality management. Spor Bilimleri Araştırmaları Dergisi, 4(2), 167-180.

137. Yüce, A., ve Sunay, H. (2019). Türkiye ve İngiltere'de yükseköğretim düzeyinde spor eğitimi sistemlerinin karşılaştırılması. Spormetre Beden Eğitimi ve Spor Bilimleri Dergisi, 17(1), 125-134.

138. Zeigler, E. F. (1995). Competency in critical thinking: a requirement for the "Allied Professional". Quest, 47(2), 196-211. 